\title{
The Effects of Hydro-Alcoholic Extract of Fenugreek Seeds on the Lipid Profile and Oxidative Stress in Fructose-Fed Rats
}

\author{
Maryam Mohammad-Sadeghipour ${ }^{1,2}$, Mehdi Afsharinasab ${ }^{3,4}$, Maryam Mohamadi ${ }^{4}$, Mehdi Mahmoodi' ${ }^{2}$, \\ Soudeh Khanamani Falahati-pour ${ }^{5}$, Mohammad Reza Hajizadeh ${ }^{3,4, *}$ \\ 'Student Research Committee and ${ }^{2}$ Department of Clinical Biochemistry, Afzalipour School of Medicine, Kerman University of Medical Sciences, Kerman; \\ ${ }^{3}$ Department of Clinical Biochemistry, Faculty of Medicine, Rafsanjan University of Medical Sciences, Rafsanjan; ${ }^{4}$ Molecular Medicine Research Center, Institute of \\ Basic Medical Sciences Research and ${ }^{5}$ Pistachio Safety Research Center, Rafsanjan University of Medical Sciences, Rafsanjan, Iran
}

Background: Metabolic syndrome (MetS) is a complex clinical disorder that can lead to an increase in oxidative stress. Patients with this syndrome are at risk of diabetes and cardiovascular disease. The Trigonella foenumgraecum L. (fenugreek) plant has many therapeutic effects, including anti-diabetic and antioxidant. The present study aimed to investigate the effects of the hydro-alcoholic extract of fenugreek seeds (HEFS) on dyslipidemia and oxidative stress due to high-fructose diet-induced MetS.

Methods: In this experimental study, to induce MetS, animals received water containing 20\% fructose for 8 weeks. After induction of MetS, 48 male Wistar rats (200-250 g) were randomized into six groups. HEFS was administered to animals at doses of 100 and $200 \mathrm{mg} / \mathrm{kg}$ orally for 4 weeks. Animal blood samples were collected to measure biochemical and antioxidant parameters of fasting plasma glucose (FPG), total cholesterol (TC), highdensity lipoprotein cholesterol (HDL-C), low-density lipoprotein cholesterol (LDL-C), triglycerides (TG), malondialdehyde (MDA), glutathione peroxidase (GPX), catalase (CAT), and total antioxidant capacity (TAC).

Results: The findings showed that the serum levels of FPG, TC, LDL-C, TG, and MDA were significantly reduced in HEFS-exposed groups compared with the control group $(P<0.05)$. Also, significant increases in HDL-C, GPX, CAT, and TAC levels $(P<0.05)$ were observed.

Conclusion: Our results revealed that treatment with HEFS increases the levels of antioxidant enzymes, decreases FPG level, and at the same time, modifies the lipid profile in MetS. Therefore, HEFS may help to alleviate the risk of some chronic complications of this disease.

Key words: Antioxidants, Dyslipidemia, Trigonella, Metabolic syndrome, Oxidative stress
Received September 7, 2019

Reviewed October 11, 2019

Accepted July 16, 2020

*Corresponding author

Mohammad Reza Hajizadeh

iD

https://orcid.org/0000-0002-1199-9601

Molecular Medicine Research Center, Rafsanjan University of Medical Sciences, Rafsanjan 7719617996, Iran

Tel: $+98-3431315023$

Fax: +98-3431315003

E-mail: hajizadehus@yahoo.com

\section{INTRODUCTION}

Metabolic syndrome (MetS) is characterized by clustering of metabolic abnormalities of central obesity, hypertension, elevated fasting plasma glucose (FPG), dyslipidemia, high body mass index, insulin resistance, and oxidative stress. ${ }^{1}$ MetS has become a significant problem in public health, with a prevalence rate of $20 \%$ to $25 \%$ among adults worldwide. ${ }^{2}$ Patients with this syndrome are at risk of various diseases, including diabetes, cardiovascular disease, ${ }^{3}$ non-alcoholic fatty liver disease, ${ }^{4}$ and cancer. ${ }^{5}$ Excessive consumption of fructose, a simple monosaccharide, is closely related to obesity. Fructose-fed rats have been reported as a rat model of $\operatorname{Met}^{6}$ and were used as such in the present study.

One of the products of biological systems is reactive oxygen species (ROS), which are highly reactive and short-lived. One of the primary methods for removal of ROS is the antioxidant system.,

Copyright ( $(2020$ Korean Society for the Study of Obesity

(a) This is an Open Access article distributed under the terms of the Creative Commons Attribution Non-Commercial License (https://creativecommons.org/licenses/by-nc/4.0/) which permits unrestricted non-commercial use, distribution, and reproduction in any medium, provided the original work is properly cited. 
The most important antioxidant enzymes include catalase (CAT), glutathione peroxidase (GPX), superoxide dismutase (SOD), and ceruloplasmin., ${ }^{9,10}$ Imbalance between ROS (increased level) and the antioxidant system (reduced antioxidants) is the leading cause of oxidative stress. ${ }^{710}$ Malondialdehyde (MDA) resulting from oxidation of unsaturated fatty acids is an important marker of oxidative stress. ${ }^{11}$

There is a relationship between oxidative stress and MetS, which aggravates MetS factors such as insulin resistance, hypertension, hypertriglyceridemia, and reduction of high-density lipoprotein cholesterol (HDL-C). ${ }^{12,13}$ The risk of MetS increases with an increase in oxidative stress. ${ }^{14}$ Recent studies have shown that MetS patients exhibit a significant reduction in activity/expression of antioxidant systems, including SOD, GPX, CAT, and reduced glutathione (GSH) ${ }^{15}$ Currently, many chemical medications are suggested for treatment and control of MetS factors, including lipidlowering agents (statins) ${ }_{1}^{16}$ insulin sensitizers (metformin, acarbose, and thiazolidinedione), ${ }^{17}$ and weight loss medications, but their various side effects limit their use. Finding a therapeutic approach with few side effects is a challenge for researchers that has prompted consideration of herbal medicines as treatment. ${ }^{18}$

Trigonella foenum-graecum L. (fenugreek) is an annual plant belonging to the family Leguminosae. ${ }^{19}$ Properties of fenugreek seeds include lowering total cholesterol (TC), triglycerides (TG), lowdensity lipoprotein cholesterol (LDL-C), and very-low-density lipoprotein cholesterol (VLDL-C) ${ }^{20}$ and being anti-diabetic, ${ }^{21}$ antitympanites, anti-diarrheal, ${ }^{20,22}$ diuretic, ${ }^{23}$ anti-inflammatory, and anti-cough..$^{24}$ Beneficial compounds, including trigonelline, 4-hydroxyisoleucine, diosgenin, orientin, luteolin flavonoids, steroid saponins, vitamins, and minerals such as iron and calcium, have been found in fenugreek seeds, ${ }^{25}$ indicating its use as a valuable therapeutic food. Moreover, studies of fenugreek in type 2 diabetes showed that active ingredients such as 4-hydroxyisoleucine, diosgenin, and galactomannan had positive effects on this pathologic state. ${ }^{24}$

Various studies have shown the effect of fenugreek on oxidative stress. ${ }^{26-28}$ One study reported that administration of aqueous extract of fenugreek plays a protective role against carbon tetrachloride-induced liver injury in rats. In that study, the ameliorative effects of the extract improved levels of serum transaminases, attenuated hepatic lipid peroxidation, and activated hepatic antioxidant enzymes. ${ }^{29}$ Another study indicated that the combination of endurance swimming training and fenugreek seed extract could significantly decrease plasma glucose level and elevate the activity of cardiac antioxidant enzymes in diabetic rats. ${ }^{30}$ Fenugreek seeds improve irradiation-induced oxidative stress by increasing GSH and SOD levels. ${ }^{31}$ Zingerone and gingerol are the most abundant compounds in the hydro-alcoholic extract of fenugreek seeds (HEFS) that have been reported to show antioxidant activity. ${ }^{32}$

Considering the seriousness and prevalence of MetS, finding a new treatment strategy to deal with this problem in modern society is important. On the other hand, no study has been performed on the antioxidant effects of fenugreek on MetS. Therefore, the present study aimed to investigate the protective effects of fenugreek seeds on the lipid profile and oxidative stress in fructose-fed rats. The extract was expected to alter the levels of antioxidants and biochemical parameters involved in MetS.

\section{METHODS}

\section{Chemicals}

Fructose, thiobarbituric acid (TBA), 1,1,3,3-tetra methoxy propane (TEP), reduced GSH, nicotinamide adenine dinucleotide phosphate (NADPH), glutathione reductase (GR), and other high-grade chemicals were purchased from Sigma Chemical Company (St. Louis, MO, USA). Hydrogen peroxide $\left(\mathrm{H}_{2} \mathrm{O}_{2}\right)$ was purchased from Merck (Darmstadt, Germany). FPG, TC, TG, LDL$\mathrm{C}$, and HDL-C were calculated using Pars Azmoon kits with an automatic analyzer (Biochemistry analyzer BT 4500; Farasamed Co., Biotechnica, Rome, Italy) for biochemical testing.

\section{Animals}

In this experimental study, adult male Wistar rats (weighing 200-250g) were obtained from the animal house of Rafsanjan University of Medical Sciences (RUMS). All the animals were kept on a $12 / 12$ light-dark schedule with a humidity of $65 \%-70 \%$ and a temperature of $22^{\circ} \mathrm{C} \pm 2^{\circ} \mathrm{C}$ and were given free access to water and food. All procedures of this study were approved by the Institutional Animal Care and Use Committee of Rafsanjan University of Medical Sciences with the IR code: IR.RUMS.REC.1395.11. 


\section{Preparation of HEFS}

The fenugreek seed was taken from the Davaran region located in Rafsanjan, Iran, and was confirmed by the Botany Research Division of the Valiasr University of Rafsanjan. The seeds were dried at room temperature and powdered in a laboratory blender (Waring Products Division, Torrington, USA). The extraction process was performed according to our previous work, ${ }^{33}$ using a Soxhlet (BAKHSHI Laboratory Industrial Co., Tehran, Iran) with a 75\% (v/v) ethanol solution. The extract yield was calculated to be $6.67 \%$.

\section{Study design and induction of MetS}

Fig. 1 depicts the study design used in the present work. Fortyeight male Wistar rats were randomly separated into control and fructose diet groups. The control group received tap water, and the fructose diet group was fed $20 \%$ fructose drinking water (FDW) daily for 8 weeks. ${ }^{6}$ The FDW was prepared by diluting $20 \mathrm{~g}$ of fructose in $100 \mathrm{~mL}$ of tap water at weight to volume; to induce MetS, D-fructose $>99 \%$ was used. The FDW was freshly prepared daily. To prevent evaporation, the bottle was covered with aluminum foil. After 8 weeks, the weight of the rats was measured using a digital scale (FEW, Tokyo, Japan), and blood samples were obtained after 12 hours fasting by penetrating the retro-orbital plexus with a capillary tube.

Subsequently, to confirm induction of MetS in rats, we analyzed indicators of MetS of body weight, FPG, TG, and TC changes in the case group after administration of $20 \%$ FDW for 8 weeks, as

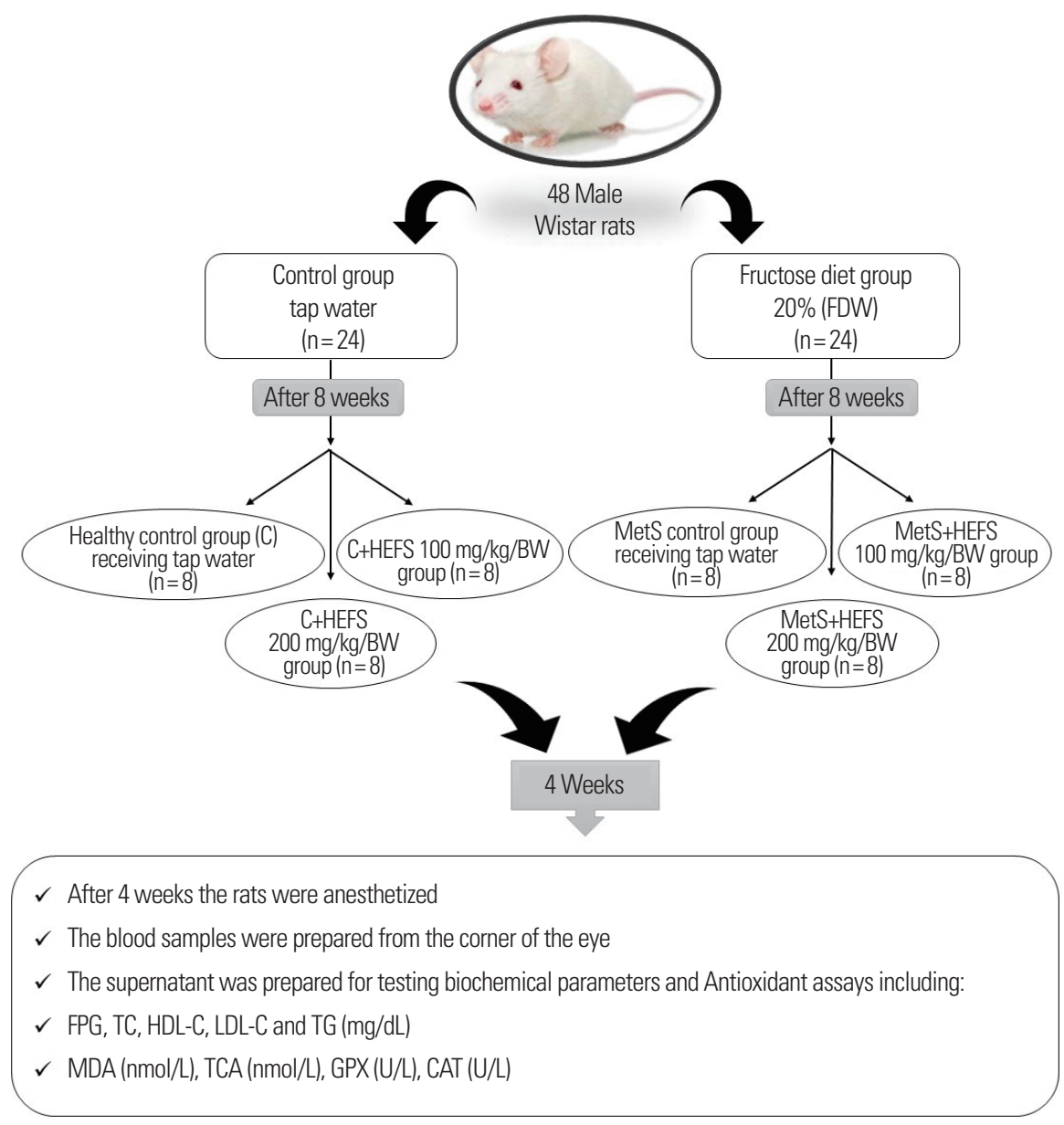

Figure 1. Schematic of the study. C: healthy control group; C+HEFS 100: healthy control group that received $100 \mathrm{mg} / \mathrm{kg} / \mathrm{BW}$ of HEFS; C+HEFS 200: healthy control group that received $200 \mathrm{mg} / \mathrm{kg} / \mathrm{BW}$ of HEFS; MetS: metabolic syndrome group that did not receive HEFS; MetS+HEFS 100: metabolic syndrome group that received $100 \mathrm{mg} / \mathrm{kg} /$ BW of HEFS; MetS+HEFS 200: metabolic syndrome group that received $200 \mathrm{mg} / \mathrm{kg} / \mathrm{BW}$ of HEFS. FDW, fructose drinking water; HEFS, hydro-alcoholic extract of fenugreek seeds; FPG, fasting plasma glucose; TC, total cholesterol; HDL-C, high-density lipoprotein cholesterol; LDL-C, low-density lipoprotein cholesterol; TG, triglycerides; MDA malondialdehyde; TCA, trichloroacetic acid; GPX, glutathione peroxidase; CAT, catalase. 
contrasted with the control group. ${ }^{34,35}$ The fructose-fed rats had significantly higher body weight, FPG, TG, and TC compared with the control rats. Therefore, the rats were enrolled in the study. Afterward, the MetS rats were randomly divided into three groups (eight rats/group): a MetS group that received no extract (MetS), a MetS group that received $100 \mathrm{mg} / \mathrm{kg} / \mathrm{BW}$ of HEFS (MetS+HEFS 100), and a MetS group that received $200 \mathrm{mg} / \mathrm{kg} / \mathrm{BW}$ of HEFS (MetS+HEFS 200). The healthy rats in the control group were also divided into three groups: a healthy group that received no extract (C), a healthy group that received $100 \mathrm{mg} / \mathrm{kg} / \mathrm{BW}$ of HEFS (C+HEFS 100), and a healthy group that received $200 \mathrm{mg} / \mathrm{kg} / \mathrm{BW}$ of HEFS (C+HEFS 200). All rats were fed a standard diet during the study. The doses of 100 and $200 \mathrm{mg} / \mathrm{kg}$ of HEFS were obtained by diluting the HEFS in physiological saline, and rats underwent intra-gastric gavage at a volume of $1 \mathrm{~mL}$ per day for 4 weeks. ${ }^{36}$ The doses of 100 and $200 \mathrm{mg} / \mathrm{kg}$ of HEFS were selected based on Gupta's study. ${ }^{37}$ All experiments were performed between 10:00 AM and 1:00 PM.

\section{Biochemical assays}

Following ethical considerations, the rats were anesthetized, and blood samples were collected from the corner of the eye in glass assay tubes without anticoagulant. The tubes were placed at room temperature to allow the blood to clot and then centrifuged at 3,000 RPM for 10 minutes. The transparent and non-hemolytic supernatant was prepared for testing biochemical parameters of FPG, TC, HDL-C, LDL-C, and TG with fitting kits (Pars Azmoun, Tehran, Iran), and the results are expressed as $\mathrm{mg} / \mathrm{dL}$.

\section{Antioxidant assays}

MDA was determined by thiobarbituric acid reactive substances (TBARS) using a colorimetric method..$^{38}$ Briefly, $0.5 \mathrm{~mL}$ of plasma was added to $2 \mathrm{~mL}$ of TBA reagent containing $0.25 \mathrm{M} / \mathrm{L} \mathrm{HCl}, 15 \mathrm{~g}$ trichloroacetic acid, and $375 \mathrm{mg}$ TBA. The mixture was boiled in a water bath at $95^{\circ} \mathrm{C}$ for 30 minutes and, after fast cooling, was centrifuged at $8,000 \mathrm{~g}$ and $4^{\circ} \mathrm{C} 15$ minutes. The MDA was determined based on the absorbance of TBA reactive substances at $532 \mathrm{~nm}$. The TBARS concentration was calculated using TEP as a standard and expressed as nmol/L of plasma.

The GPX activity of the serum samples was defined by the coupled enzymatic reaction at $25^{\circ} \mathrm{C}$ according to the method of Paglia and Valentine. ${ }^{39}$ Briefly, the enzymatic reaction in a cuvette that contained $\mathrm{NADPH}, \mathrm{NaN}_{3}, \mathrm{GSH}$, and GR was initiated by adding $\mathrm{H}_{2} \mathrm{O}_{2}$, and the change in absorbance was monitored spectrophotometrically at $340 \mathrm{~nm}$. The result was expressed as U/L of plasma.

Serum CAT activity was determined according to the procedure of Aebi with $\mathrm{H}_{2} \mathrm{O}_{2}(30 \mathrm{mM})$ as the substrate. ${ }^{40}$ To $100 \mathrm{~mL}$ of $30 \mathrm{mmol} / \mathrm{L} \mathrm{H}_{2} \mathrm{O}_{2}$ solution in $350 \mathrm{~mL}$ phosphate buffer ( $\mathrm{pH} 7.0$ ), $50 \mathrm{~mL}$ of serum sample was added, and the consumption of $\mathrm{H}_{2} \mathrm{O}_{2}$ was followed spectrophotometrically at $240 \mathrm{~nm}$ for 3 minutes at $25^{\circ} \mathrm{C}$ and expressed as U/L of plasma. Total antioxidant capacity (TAC) was determined by the ferric reducing antioxidant power assay (FRAP assay). ${ }^{41}$ Data were expressed as $\mathrm{mmol} / \mathrm{L}$ in plasma.

\section{Statistical analysis}

Results are reported as mean \pm standard error of the mean where indicated. One-way analysis of variance followed by Tukey's multiple comparisons test was used to analyze the data from the biochemical and oxidative stress assessments before and after treatment. Paired sample t-test was used to compare the variables before and after the intervention. Statistical results were evaluated using the SPSS version 18 (SPSS, Chicago, IL, USA). The significance level was $P<0.05$.

\section{RESULTS}

To confirm that the rats acquired MetS, changes in FPG, TG, TC, and weight were considered after 8 weeks of drinking water containing 20\% fructose. A significant increase $(P<0.001)$ in the levels of FPG (125.00 $\pm 3.52 \mathrm{mg} / \mathrm{dL})$, TG $(142.62 \pm 6.62 \mathrm{mg} / \mathrm{dL})$, TC $(97.75 \pm 2.11 \mathrm{mg} / \mathrm{dL})$, and weight $(290.62 \pm 6.18 \mathrm{~g})$ was observed in the rats that received fructose (MetS group) compared with the healthy control group (C), indicating induction of MetS in the rats (Table 1).

\section{Changes in biochemical parameters after extract administration}

Administration of HEFS (100 and $200 \mathrm{mg} / \mathrm{kg} / \mathrm{BW}$ ) in the MetS and healthy groups resulted in significant decrease in FPG, TG, 
Table 1. Changes in biochemical parameters of the studied groups after the intervention compared with the baseline

\begin{tabular}{|c|c|c|c|c|c|c|}
\hline \multirow{2}{*}{ Variable } & \multicolumn{6}{|c|}{ Group } \\
\hline & C & C+HEFS 100 & C+HEFS 200 & MetS & MetS+HEFS 100 & MetS+HEFS 200 \\
\hline \multicolumn{7}{|c|}{$\mathrm{FPG}(\mathrm{mg} / \mathrm{dL})$} \\
\hline Before & $95.87 \pm 1.85$ & $93.11 \pm 2.84$ & $93.37 \pm 2.75$ & $125.00 \pm 3.52^{*}$ & $130.00 \pm 1.58$ & $134.00 \pm 3.82$ \\
\hline After & $95.37 \pm 2.16$ & $88.77 \pm 2.72^{\dagger}$ & $89.75 \pm 2.95^{\ddagger}$ & $127.25 \pm 3.49^{*}$ & $121.44 \pm 2.35^{\ddagger}$ & $122.75 \pm 2.90^{\dagger}$ \\
\hline \multicolumn{7}{|c|}{$\mathrm{TG}(\mathrm{mg} / \mathrm{dL})$} \\
\hline Before & $76.50 \pm 2.01$ & $79.88 \pm 1.98$ & $72.12 \pm 1.96$ & $142.62 \pm 6.62^{*}$ & $155.44 \pm 4.74$ & $160.25 \pm 4.71$ \\
\hline After & $79.75 \pm 2.06$ & $75.44 \pm 2.30^{\ddagger}$ & $64.37 \pm 1.05^{\ddagger}$ & $146.00 \pm 6.76^{*}$ & $145.88 \pm 5.22^{\S}$ & $138.12 \pm 4.29^{\S}$ \\
\hline \multicolumn{7}{|c|}{$\mathrm{TC}$ (mg/dL) } \\
\hline Before & $79.00 \pm 3.24$ & $78.55 \pm 2.45$ & $74.87 \pm 2.37$ & $97.75 \pm 2.11^{*}$ & $115.44 \pm 4.97$ & $107.62 \pm 5.24$ \\
\hline After & $79.37 \pm 2.57$ & $73.88 \pm 1.30^{\dagger}$ & $65.37 \pm 3.13^{\S}$ & $99.75 \pm 1.93^{*}$ & $103.33 \pm 5.19^{\dagger}$ & $91.62 \pm 6.90^{\ddagger}$ \\
\hline \multicolumn{7}{|c|}{ LDL-C (mg/dL) } \\
\hline Before & $35.75 \pm 2.72$ & $36.88 \pm 2.45$ & $29.62 \pm 1.61$ & $43.75 \pm 2.78$ & $62.77 \pm 4.72$ & $50.75 \pm 5.54$ \\
\hline After & $37.50 \pm 2.32$ & $33.00 \pm 2.29^{\ddagger}$ & $25.62 \pm 1.38^{\ddagger}$ & $45.00 \pm 3.56$ & $56.88 \pm 5.40^{\dagger}$ & $40.25 \pm 5.02^{\ddagger}$ \\
\hline \multicolumn{7}{|c|}{$\mathrm{HDL}-\mathrm{C}(\mathrm{mg} / \mathrm{dL})$} \\
\hline Before & $29.62 \pm 1.26$ & $26.33 \pm 0.97$ & $36.37 \pm 1.03$ & $30.50 \pm 1.10$ & $23.88 \pm 1.16$ & $26.25 \pm 1.12$ \\
\hline After & $30.00 \pm 1.22$ & $29.66 \pm 0.93^{\S}$ & $39.25 \pm 1.72^{\dagger}$ & $30.37 \pm 1.14$ & $29.88 \pm 0.87^{\S}$ & $34.75 \pm 1.72^{\S}$ \\
\hline \multicolumn{7}{|c|}{ Weight (g) } \\
\hline Before & $224.00 \pm 3.64$ & $218.00 \pm 6.32$ & $228.50 \pm 3.25$ & $290.62 \pm 6.18^{*}$ & $302.00 \pm 4.09$ & $290.62 \pm 6.71$ \\
\hline After & $241.87 \pm 2.97$ & $229.00 \pm 6.46^{\dagger}$ & $238.50 \pm 4.98^{\dagger}$ & $303.62 \pm 6.44^{*}$ & $310.55 \pm 2.81^{\ddagger}$ & $298.87 \pm 4.34^{\dagger}$ \\
\hline \multicolumn{7}{|c|}{ MDA (nmol/L) } \\
\hline Before & $31.50 \pm 1.41$ & $30.00 \pm 1.24$ & $23.12 \pm 0.58$ & $60.75 \pm 4.46^{*}$ & $79.11 \pm 2.50$ & $80.00 \pm 3.30$ \\
\hline After & $28.50 \pm 1.73$ & $31.78 \pm 1.30$ & $21.62 \pm 1.17$ & $63.12 \pm 3.89^{\dagger}$ & $74.78 \pm 3.05^{\dagger}$ & $67.78 \pm 3.14^{\ddagger}$ \\
\hline \multicolumn{7}{|c|}{$\mathrm{GPX}(\mathrm{U} / \mathrm{L})$} \\
\hline Before & $47.50 \pm 1.29$ & $53.44 \pm 2.27$ & $48.50 \pm 1.87$ & $41.75 \pm 1.75^{*}$ & $44.22 \pm 1.03$ & $30.87 \pm 1.75$ \\
\hline After & $44.87 \pm 3.44$ & $57.56 \pm 1.91^{\dagger}$ & $58.87 \pm 1.85^{\S}$ & $39.75 \pm 1.76$ & $45.00 \pm 1.92$ & $37.75 \pm 2.18^{\dagger}$ \\
\hline \multicolumn{7}{|c|}{ CAT (U/L) } \\
\hline Before & $30.62 \pm 1.11$ & $28.78 \pm 1.03$ & $27.50 \pm 1.52$ & $22.00 \pm 1.03^{*}$ & $22.44 \pm 1.30$ & $19.62 \pm 0.92$ \\
\hline After & $31.87 \pm 1.30$ & $31.33 \pm 1.52$ & $36.00 \pm 1.41^{\S}$ & $21.87 \pm 0.87$ & $23.33 \pm 1.00$ & $25.25 \pm 1.25^{\ddagger}$ \\
\hline \multicolumn{7}{|c|}{ TAC (mmol/L) } \\
\hline Before & $1.14 \pm 0.08$ & $1.00 \pm 0.10$ & $0.94 \pm 0.09$ & $0.49 \pm 0.05$ & $0.43 \pm 0.07$ & $0.45 \pm 0.06$ \\
\hline After & $1.11 \pm 0.08$ & $1.28 \pm 0.15$ & $1.31 \pm 0.16$ & $0.39 \pm 0.03^{*}$ & $0.58 \pm 0.08^{\S}$ & $0.86 \pm 0.09^{\S}$ \\
\hline
\end{tabular}

C: healthy control group; C+HEFS 100: healthy control group that received $100 \mathrm{mg} / \mathrm{kg} / \mathrm{BW}$ of HEFS; C+HEFS 200: healthy control group that received $200 \mathrm{mg} / \mathrm{kg} / \mathrm{BW}$ of HEFS; MetS: metabolic syndrome group that did not receive HEFS; MetS+HEFS 100: metabolic syndrome group that received $100 \mathrm{mg} / \mathrm{kg} / \mathrm{BW}$ of HEFS; MetS+HEFS 200: metabolic syndrome group that received $200 \mathrm{mg} / \mathrm{kg} / \mathrm{BW}$ of HEFS.

${ }^{*} P<0.001$ : indicates a significant difference from the healthy control group; ${ }^{\dagger} P<0.05,{ }^{\ddagger} P<0.01,{ }^{\S} P<0.001$ : indicates a significant difference before and after the intervention in each group.

HEFS, hydro-alcoholic extract of fenugreek seeds; MetS, metabolic syndrome; FPG, fasting plasma glucose; TG, triglycerides; TC, total cholesterol; LDL-C, low-density lipoprotein cholesterol; HDL-C, high-density lipoprotein cholesterol; MDA, malondialdehyde; GPX, glutathione peroxidase; CAT, catalase; TAC, total antioxidant capacity.

TC, and LDL-C levels. MDA level was decreased significantly only in the MetS groups after administration of HEFS (100 and 200 $\mathrm{mg} / \mathrm{kg} / \mathrm{BW})$. In the MetS group that received $100 \mathrm{mg} / \mathrm{kg} / \mathrm{BW}$ of HEFS, no significant change in the levels of GPX and CAT was observed in comparison to those before treatment. However, the levels of GPX, CAT, and TAC increased significantly after treatment with $200 \mathrm{mg} / \mathrm{kg} / \mathrm{BW}$ of HEFS. In the healthy groups, the levels of GPX and CAT increased considerably $(P<0.001)$ after treatment with $200 \mathrm{mg} / \mathrm{kg} / \mathrm{BW}$ of HEFS. However, in the healthy C+HEFS 100 and C+HEFS 200 groups of Table 1, there was no significant decrease in MDA level and no significant increase in activity level of TAC after administration of HEFS (100 and $200 \mathrm{mg} / \mathrm{kg} / \mathrm{BW}$ ). In both MetS and healthy groups, treatment with HEFS significantly decreased the TG level; this decrease was higher in the treated MetS groups. In the MetS groups receiving HEFS at the dose of $200 \mathrm{mg} / \mathrm{kg} / \mathrm{BW}$ compared with the dose of $100 \mathrm{mg} / \mathrm{kg} / \mathrm{BW}$, mean 
HDL-C $(P=0.030)$ and LDL-C $(P=0.040)$ significantly increased and decreased, respectively. The mean weight of the healthy groups that received 100 and $200 \mathrm{mg} / \mathrm{kg} / \mathrm{BW}$ of HEFS was lower than those of the MetS control and healthy control groups after the intervention. It can be concluded that use of HEFS may have a role in weight loss (Table 1).

\section{Changes in antioxidant activity}

The results of antioxidant assessments at baseline were compared between the MetS group and the healthy group. The mean serum MDA level $(60.75 \pm 4.46 \mathrm{nmol} / \mathrm{L}, P<0.001)$ increased, and the activity levels of CAT $(22.00 \pm 1.03 \mathrm{U} / \mathrm{L})$ and TAC $(0.49 \pm 0.05$ $\mathrm{mmol} / \mathrm{L})$ significantly decreased $(P<0.001)$, resulting in a decrease in the activity level of GPX $(41.75 \pm 1.75 \mathrm{U} / \mathrm{L}, P=0.020)$. Overall, these results indicate oxidative stress in the MetS rats (Table 1).

The mean serum MDA level in rats after the intervention was significantly reduced in the MetS groups receiving HEFS at doses of $100(P=0.038)$ and $200 \mathrm{mg} / \mathrm{kg} / \mathrm{BW}(P<0.001)$. This decrease was greater with the dose of $200 \mathrm{mg} / \mathrm{kg} / \mathrm{BW}(P<0.001)$ (Table 1$)$. A significant increase in MDA level in the MetS control group after the intervention compared with baseline could be indicative of disease progression and increased oxidative stress in the rats $(P=0.043)$. The serum levels of GPX and CAT increased in the groups receiving HEFS, and the increases were significant in the MetS group and the healthy group receiving HEFS at the dose of $200 \mathrm{mg} / \mathrm{kg} / \mathrm{BW}$. In the healthy group receiving HEFS at the dose of $100 \mathrm{mg} / \mathrm{kg} / \mathrm{BW}$, the increase was significant only for GPX $(P=0.036)$. The TAC level showed a significant decrease after the intervention in the MetS control group $(P<0.001)$. As mentioned, this can indicate progression of MetS due to oxidative stress. Administration of HEFS increased the TAC level significantly in all recipient groups. However, this increase was only significant in the MetS groups receiving HEFS at both doses $(P<0.001)$ (Table 1$)$.

\section{DISCUSSION}

MetS is a collection of symptoms including abdominal obesity, hypertriglyceridemia, hyperglycemia, and high blood pressure, and a decrease in HDL-C level that depend on lifestyle. ${ }^{42}$ The World Health Organization considers the presence of three or more of these conditions to be MetS, which is also known as syndrome X, insulin resistance syndrome, and the deadly quartet syndrome. ${ }^{43,44}$ Studies have shown that insulin resistance is a major disorder in MetS, which is associated with oxidative stress. ${ }^{45}$

Our results showed that a long-term fructose diet (20\% fructose in drinking water) induces MetS in rats, accompanied by increased body weight and blood glucose and abnormalities in lipid profile (increase in TC, LDL-C, and TG levels and decrease in HDL-C content), as well as oxidative stress dysregulation (decrease in TAC, lower enzyme activity of CAT and GPX, and elevated MDA serum level).

Also, the present study showed that oral administration of HEFS at doses of 100 and $200(\mathrm{mg} / \mathrm{kg} / \mathrm{BW})$ for one month significantly reduced the levels of FPG, TC, LDL-C, and TG and increased those of HDL-C and antioxidants of GPX and CAT, as well as TAC, compared with the control group. In the MetS groups receiving the, the TAC and CAT values were significantly increased compared with the MetS control group, and this increase was significant at the dose of $200 \mathrm{mg} / \mathrm{kg} / \mathrm{BW}$.

A study showed that fenugreek seeds increase the secretion of glucose-dependent insulin from the beta cells of the islets of Langerhans in rats, thereby reducing serum glucose. In addition, fenugreek seeds were found to decrease insulin resistance in the muscles and liver by activating insulin receptors and phosphoinositide 3-kinase. ${ }^{46}$ Fenugreek seeds also reduced blood glucose by delaying glucose intake in the intestine and increasing cellular consumption. ${ }^{47}$ The fibers of fenugreek seeds delay digestion and absorption of carbohydrates by slowing stomach emptying, inhibiting the activity of the enzyme disaccharidase and the glucose carrier in the intestine, and increasing insulin activity. ${ }^{48,49}$ The alcoholic extract of fenugreek seeds inhibits glucose uptake by inhibiting the intestinal amylase enzyme and suppressing liver gluconeogenesis. On the other hand, it increases glucose 6-phosphate dehydrogenase activity and the hexose monophosphate pathway to ultimately increase glucose metabolism. ${ }^{36}$

In line with our findings, Ramadan et al. ${ }^{36}$ showed that Egyptian fenugreek seed powder increased GPX activity and reduced TC, total lipids, triacylglycerol, and plasma glucose levels in rats receiving doses of 100 and $500 \mathrm{mg} / \mathrm{kg} / \mathrm{BW}$ compared with the control group. These alterations were dose-dependent. ${ }^{36}$ Sharma and Choudhary ${ }^{50}$ 
evaluated the effects of fenugreek seeds and compared them to those of atorvastatin in hyperlipidemic rabbits. They reported that fenugreek powder and its extracts significantly reduced TC, LDL-C, and TG levels in rabbits after 4 weeks of treatment, while HDL-C level increased in the rabbits treated with fenugreek powder and its extracts. In this study, the levels of TC, LDL-C, and TG decreased significantly in all groups receiving the extract. ${ }^{50}$ Another study reported that TC, LDL-C, and TG levels in hyperlipidemic rabbits significantly decreased after 4 weeks of treatment with $500 \mathrm{mg} / \mathrm{kg} /$ BW of HEFS. In addition, consistent with our study, the HDL-C level increased significantly, but VLDL-C did not change. ${ }^{51}$

Previous studies demonstrated that reductions in plasma levels of TC, TG, and LDL-C are related to the presence of saponins in fenugreek seed extract. ${ }^{52,53}$ Marzouk et al. ${ }^{54}$ demonstrated that fenugreek seed powder could decrease total lipids, TC, TG, and liver enzymes such as alanine transaminase and aspartate transaminase. At the same time, it increased ALP, GSH, glutathione S-transferase, and CAT compared with a diabetic control group. Findings from an animal study indicated that TC, TG, LDL-C, and VLDL-C in the liver and heart decreased in rats fed a high-fat diet that received doses of 100 and $200 \mathrm{mg} / \mathrm{kg} / \mathrm{BW}$ of aqueous extract of fenugreek seeds. Furthermore, the HDL-C level increased, and the level of GSH and activity of SOD and CAT were significantly higher in comparison to the control group fed a high-fat diet. ${ }^{55}$

In our study, a significant decrease in the levels of glucose and MDA in the groups receiving the extract was observed compared with the control groups. Another experimental study reported increased levels of lipoprotein lipase, TG lipase, deoxycholic acid, and cholic acid in the liver tissue of rats that received alcoholic extract of fenugreek seeds. ${ }^{56}$

It was demonstrated that the aqueous extract of fenugreek seeds decreased the levels of insulin, homeostatic model assessment of insulin resistance, TG, and TC in fructose-fed insulin-resistant rats. In contrast, the levels of HDL-C, adiponectin, glucose, and peroxisome proliferator-activated receptor gamma protein increased. The body weight of the rats did not change significantly in that study. ${ }^{57}$ Another study has revealed that 4-hydroxyisoleucine, an atypical branched-chain amino acid derived from fenugreek, is responsible for the effect of this plant on glucose and lipid metabolism. ${ }^{46}$ The 4-hydroxyisoleucine directly affects the pancreatic islets and subse- quently stimulates glucose-dependent insulin secretion, as well as decreasing the elevated levels of TG and TC in diabetic hamsters. Therefore, 4-hydroxyisoleucine can be an effective herbal medicine for treatment of diabetes, obesity, and the main components of MetS. ${ }^{46}$ The findings of our study show that doses of 100 and 200 $\mathrm{mg} / \mathrm{kg} / \mathrm{BW}$ of HEFS might have a considerable effect on MetS, and the dose of $200 \mathrm{mg} / \mathrm{kg} / \mathrm{BW}$ had a greater effect than the dose of $100 \mathrm{mg} / \mathrm{kg} / \mathrm{BW}$ on some of the parameters.

According to the findings of this study, HEFS increases the levels of antioxidant enzymes, decreases FPG level, and modifies the lipid profile in MetS. In summary, this extract shows hypoglycemic, hypolipidemic, and antioxidant effects, so it may be helpful in alleviating the risk of some chronic complications of MetS. However, it seems that treatment for 8 weeks is not sufficient to regulate the measured parameters thoroughly since none of the parameters has reached the level seen in the healthy control group. Furthermore, understanding the detailed molecular and cellular mechanisms affecting the pharmacological function of fenugreek seeds extract on the treatment or control of MetS and other diseases with etiologies of dyslipidemia and oxidative stress requires further and comprehensive studies to enhance the knowledge of the potential effects of this medicinal plant.

\section{CONFLICTS OF INTEREST}

The authors declare no conflict of interest.

\section{ACKNOWLEDGMENTS}

The authors are thankful for the support by RUMS under grant number 20.198 .

\section{AUTHOR CONTRIBUTIONS}

Study concept and design: MMS; acquisition of data: MMS; analysis and interpretation of data: MMS, MA; drafting of the manuscript: MMS, SKF, MeM; critical revision of the manuscript: MaM; statistical analysis: MMS, MaM; obtained funding: $\mathrm{MRH}$; administrative, technical, or material support: $\mathrm{MRH}$; and study supervision: MRH. 


\section{REFERENCES}

1. Kaur J. A comprehensive review on metabolic syndrome. Cardiol Res Pract 2014;2014:943162.

2. Eckel RH, Alberti KG, Grundy SM, Zimmet PZ. The metabolic syndrome. Lancet 2010;375:181-3.

3. Loftus HL, Astell KJ, Mathai ML, Su XQ. Coleus forskohlii extract supplementation in conjunction with a hypocaloric diet reduces the risk factors of metabolic syndrome in overweight and obese subjects: a randomized controlled trial. $\mathrm{Nu}-$ trients 2015;7:9508-22.

4. Bocco BM, Fernandes GW, Lorena FB, Cysneiros RM, Christoffolete MA, Grecco SS, et al. Combined treatment with caffeic and ferulic acid from Baccharis uncinella C. DC. (Asteraceae) protects against metabolic syndrome in mice. Braz J Med Biol Res 2016;49:e5003.

5. Uzunlulu M, Telci Caklili O, Oguz A. Association between metabolic syndrome and cancer. Ann Nutr Metab 2016;68: 173-9.

6. Mamikutty N, Thent ZC, Sapri SR, Sahruddin NN, Mohd Yusof MR, Haji Suhaimi F. The establishment of metabolic syndrome model by induction of fructose drinking water in male Wistar rats. Biomed Res Int 2014;2014:263897.

7. Luque-Contreras D, Carvajal K, Toral-Rios D, Franco-Bocanegra D, Campos-Peña V. Oxidative stress and metabolic syndrome: cause or consequence of Alzheimer's disease? Oxid Med Cell Longev 2014;2014:497802.

8. López-Acosta O, de Los Angeles Fortis-Barrera M, BarriosMaya MA, Ramírez AR, Aguilar FJA, El-Hafidi M. Reactive oxygen species from NADPH oxidase and mitochondria participate in the proliferation of aortic smooth muscle cells from a model of metabolic syndrome. Oxid Med Cell Longev 2018; 2018:5835072.

9. Hopps E, Noto D, Caimi G, Averna MR. A novel component of the metabolic syndrome: the oxidative stress. Nutr Metab Cardiovasc Dis 2010;20:72-7.

10. Roberts CK, Sindhu KK. Oxidative stress and metabolic syndrome. Life Sci 2009;84:705-12.

11. Ho E, Karimi Galougahi K, Liu CC, Bhindi R, Figtree GA. Biological markers of oxidative stress: applications to cardio- vascular research and practice. Redox Biol 2013;1:483-91.

12. Vincent HK, Taylor AG. Biomarkers and potential mechanisms of obesity-induced oxidant stress in humans. Int J Obes (Lond) 2006;30:400-18.

13. Fujita T. Aldosterone in salt-sensitive hypertension and metabolic syndrome. J Mol Med (Berl) 2008;86:729-34.

14. Chung SW, Kang SG, Rho JS, Kim HN, Song IS, Lee YA, et al. The association between oxidative stress and metabolic syndrome in adults. Korean J Fam Med 2013;34:420-8.

15. Vona R, Gambardella L, Cittadini C, Straface E, Pietraforte D. Biomarkers of oxidative stress in metabolic syndrome and associated diseases. Oxid Med Cell Longev 2019;2019:8267234.

16. Ott C, Schmieder RE. The role of statins in the treatment of the metabolic syndrome. Curr Hypertens Rep 2009;11:143-9.

17. Mora S, Ridker PM. Justification for the use of statins in primary prevention: an Intervention Trial Evaluating Rosuvastatin (JUPITER): can C-reactive protein be used to target statin therapy in primary prevention? Am J Cardiol 2006;97(2A): 33A-41A.

18. Rao BK, Kesavulu MM, Giri R, Appa Rao C. Antidiabetic and hypolipidemic effects of Momordica cymbalaria Hook: fruit powder in alloxan-diabetic rats. J Ethnopharmacol 1999;67: 103-9.

19. Bafadam S, Beheshti F, Khodabakhshi T, Asghari A, Ebrahimi B, Sadeghnia HR, et al. Trigonella foenum-graceum seed (Fenugreek) hydroalcoholic extract improved the oxidative stress status in a rat model of diabetes-induced memory impairment. Horm Mol Biol Clin Investig 2019;39:20180074.

20. Prasanna M. Hypolipidemic effect of fenugreek: a clinical study. Indian J Pharmacol 2000;32:34-6.

21. Srivastava A, Singh Z, Verma V, Choedon T. Potential health benefits of fenugreek with multiple pharmacological properties. In: Mishra N, editor. Ethnopharmacological investigation of Indian spices. Hershey: IGI Global; 2020. p. 137-53.

22. Chaudhuri RD. Herbal drugs industry: practical approach to industrial pharmacognosy. New Delhi: Eastern; 1996.

23. Mallik S, Sharangi AB, Sarkar T. Phytochemicals of coriander, cumin, fenugreek, fennel and black cumin: a preliminary study. Natl Acad Sci Lett 2020 Jan 30 [Epub]. https://doi.org/10. $1007 /$ s40009-020-00884-5 
24. Koupý D, Kotolová H, Rudá Kučerová J. Effectiveness of phytotherapy in supportive treatment of type 2 diabetes mellitus II. Fenugreek (Trigonella foenum-graecum). Ceska Slov Farm 2015;64:67-71.

25. Skidmore-Roth L. Mosby's handbook of herbs \& natural supplements. Amsterdam: Elsevier; 2009.

26. Prema A, Justin Thenmozhi A, Manivasagam T, Mohamed Essa M, Guillemin GJ. Fenugreek seed powder attenuated aluminum chloride-induced tau pathology, oxidative stress, and inflammation in a rat model of Alzheimer's disease. J Alzheimers Dis 2017;60(s1):S209-20.

27. Pradeep SR, Srinivasan K. Amelioration of oxidative stress by dietary fenugreek (Trigonella foenum-graecum L.) seeds is potentiated by onion (Allium cepa L.) in streptozotocin-induced diabetic rats. Appl Physiol Nutr Metab 2017;42:816-28.

28. Tavakoly R, Maracy MR, Karimifar M, Entezari MH. Does fenugreek (Trigonella foenum-graecum) seed improve inflammation, and oxidative stress in patients with type 2 diabetes mellitus? A parallel group randomized clinical trial. Eur J Integr Med 2018;18:13-7.

29. Al-Sultan SI, El-Bahr SM. Effect of aqueous extract of fenugreek (Trigonella foenum-graecum L.) on selected biochemical and oxidative stress biomarkers in rats intoxicated with carbon tetrachloride. Int J Pharmacol 2015;11:43-9.

30. Arshadi S, Bakhtiyari S, Haghani K, Valizadeh A. Effects of fenugreek seed extract and swimming endurance training on plasma glucose and cardiac antioxidant enzymes activity in streptozotocin-induced diabetic rats. Osong Public Health Res Perspect 2015;6:87-93.

31. Alrasheedi A, Al-Aamri S, Eassawy M, Bawazeer F. Effect of fenugreek seeds against irradiation-induced oxidative stress in adult rats. World J Dairy Food Sci 2016;11:37-51.

32. Al-Daghri NM, Alokail MS, Alkharfy KM, Mohammed AK, Abd-Alrahman SH, Yakout SM, et al. Fenugreek extract as an inducer of cellular death via autophagy in human T lymphoma Jurkat cells. BMC Complement Altern Med 2012;12:202.

33. Mohammad-Sadeghipour M, Mahmoodi M, Falahati-pour SK, Khoshdel A, Fahmidehkar MA, Mirzaei MR, et al. Trigonella foenum-graecum seed extract modulates expression of lipid metabolism- related genes in HepG2 cells. Asian Pac J
Trop Biomed 2019;9:240-8.

34. Hsieh CC, Liao CC, Liao YC, Hwang LS, Wu LY, Hsieh SC. Proteomic changes associated with metabolic syndrome in a fructose-fed rat model. J Food Drug Anal 2016;24:754-61.

35. Ibrahim SM, El-Denshary ES, Abdallah DM. Geraniol, alone and in combination with pioglitazone, ameliorates fructose-induced metabolic syndrome in rats via the modulation of both inflammatory and oxidative stress status. PLoS One 2015;10: e0117516.

36. Ramadan G, El-Beih NM, Abd El-Kareem HF. Anti-metabolic syndrome and immunostimulant activities of Egyptian fenugreek seeds in diabetic/obese and immunosuppressive rat models. Br J Nutr 2011;105:995-1004.

37. Gupta SK, Kumar B, Nag TC, Srinivasan BP, Srivastava S, Gaur S, et al. Effects of Trigonella foenum-graecum (L.) on retinal oxidative stress, and proinflammatory and angiogenic molecular biomarkers in streptozotocin-induced diabetic rats. Mol Cell Biochem 2014;388:1-9.

38. Brown RK, Kelly FJ. Peroxides and other products. In: Punchard NA, Kelly FJ, editors. Free radicals: a practical approach. New York: IRL Press; 1996. p. 119-31.

39. Paglia DE, Valentine WN. Studies on the quantitative and qualitative characterization of erythrocyte glutathione peroxidase. J Lab Clin Med 1967;70:158-69.

40. Aebi H. Catalase. In: Bergmeyer HU, editor. Methods of enzymatic analysis. 2nd ed. Amsterdam: Elsevier; 1974. p. 673-84.

41. Benzie IF, Strain JJ. The ferric reducing ability of plasma (FRAP) as a measure of "antioxidant power": the FRAP assay. Anal Biochem 1996;239:70-6.

42. Rostami H, Tavakoli HR, Rahimi MH, Mohammadi M. Metabolic syndrome prevalence among armed forces personnel (military personnel and police officers): a systematic review and meta-analysis. Mil Med 2019;184:e417-25.

43. Devlin TM. Textbook of biochemistry with clinical correlations. Hoboken (NJ): Wiley; 2010.

44. Nambi V, Hoogwerf BJ, Sprecher DL. A truly deadly quartet: obesity, hypertension, hypertriglyceridemia, and hyperinsulinemia. Cleve Clin J Med 2002;69:985-9.

45. Carrier A. Metabolic syndrome and oxidative stress: a complex relationship. Antioxid Redox Signal 2017;26:429-31. 
46. Jetté L, Harvey L, Eugeni K, Levens N. 4-Hydroxyisoleucine: a plant-derived treatment for metabolic syndrome. Curr Opin Investig Drugs 2009;10:353-8.

47. Hannan JM, Ali L, Rokeya B, Khaleque J, Akhter M, Flatt PR, et al. Soluble dietary fibre fraction of Trigonella foenum-graecum (fenugreek) seed improves glucose homeostasis in animal models of type 1 and type 2 diabetes by delaying carbohydrate digestion and absorption, and enhancing insulin action. $\mathrm{Br} \mathrm{J}$ Nutr 2007;97:514-21.

48. Srichamroen A, Thomson AB, Field CJ, Basu TK. In vitro intestinal glucose uptake is inhibited by galactomannan from Canadian fenugreek seed (Trigonella foenum graecum L) in genetically lean and obese rats. Nutr Res 2009;29:49-54.

49. Mathern JR, Raatz SK, Thomas W, Slavin JL. Effect of fenugreek fiber on satiety, blood glucose and insulin response and energy intake in obese subjects. Phytother Res 2009;23:1543-8.

50. Sharma MS, Choudhary PR. Hypolipidemic effect of fenugreek seeds and its comparison with atorvastatin on experimentally induced hyperlipidemia. J Coll Physicians Surg Pak 2014;24: 539-42.

51. Sharma MS, Choudhary PR. Effect of fenugreek seeds powder (Trigonella foenum-graecum L.) on experimental induced hyperlipidemia in rabbits. J Diet Suppl 2017;14:1-8.
52. Thompson Coon JS, Ernst E. Herbs for serum cholesterol reduction: a systematic view. J Fam Pract 2003;52:468-78.

53. Baquer NZ, Kumar P, Taha A, Kale RK, Cowsik SM, McLean P. Metabolic and molecular action of Trigonella foenum-graecum (fenugreek) and trace metals in experimental diabetic tissues. J Biosci 2011;36:383-96.

54. Marzouk M, Soliman AM, Omar TY. Hypoglycemic and antioxidative effects of fenugreek and termis seeds powder in streptozotocin-diabetic rats. Eur Rev Med Pharmacol Sci 2013;17: 559-65.

55. Kumar P, Bhandari U, Jamadagni S. Fenugreek seed extract inhibit fat accumulation and ameliorates dyslipidemia in high fat diet-induced obese rats. Biomed Res Int 2014;2014:606021.

56. Chaturvedi U, Shrivastava A, Bhadauria S, Saxena JK, Bhatia G. A mechanism-based pharmacological evaluation of efficacy of Trigonella foenum graecum (fenugreek) seeds in regulation of dyslipidemia and oxidative stress in hyperlipidemic rats. J Cardiovasc Pharmacol 2013;61:505-12.

57. Mohammadi A, Gholamhosseinian A, Fallah H. Trigonella foenum-graecum water extract improves insulin sensitivity and stimulates PPAR and $\gamma$ gene expression in high fructose-fed insulin-resistant rats. Adv Biomed Res 2016;5:54. 